\title{
BioMIPs - Desenvolvimento de Anticorpos Plásticos para Reconhecimento de Biomoléculas Utilizando uma Estratégia Verde
}

Vasco Bonifácio

vasco.bonifacio@tecnico.ulisboa.pt
- - A indústria biofarmacêutica tem aumentado significativamente a sua produção nos últimos anos. É expectável que o mercado biofarmacêutico global atinga os 435 milhões de euros até 2025, com uma taxa de crescimento anual de 13,8\%. No entanto, este aumento de produção não tem sido acompanhado com a necessária evolução e scale up de processos sustentáveis de purificação. A purificação é um processo complexo, com múltiplos estágios, e representa entre 50 e $80 \%$ dos custos de produção.

0 projeto BioMIPs tem como principal objetivo desenhar e desenvolver partículas poliméricas inovadoras e competitivas para purificação, nomeadamente com capacidade de reconhecimento molecular para biomoléculas. 0 seu modo de atuação é inspirado em anticorpos naturais ou enzimas, num mecanismo de lock and key. Será utilizada uma tecnologia limpa, o dióxido de carbono supercrítico $\left(\mathrm{scCO}_{2}\right)$, combinada com a impressão molecular. A ideia-chave é sintetizar materiais robustos de elevada afinidade, de baixo custo, com elevada potencialidade em diversas indústrias, kits de sensores, etc. As partículas são obtidas já secas e puras, sem vestígios de solvente $\left(\mathrm{o} \mathrm{CO}_{2}\right.$ liberta-se do material), com tamanho homogéneo e de fácil manuseamento. A validação destes materiais será feita em parceria com uma empresa portuguesa de biofungicidas, utilizando misturas-modelo e amostras reais. Espera-se que os BioMIPs tenham impacto na diminuição dos custos de purificação e consequentemente no custo de produção dos medicamentos.

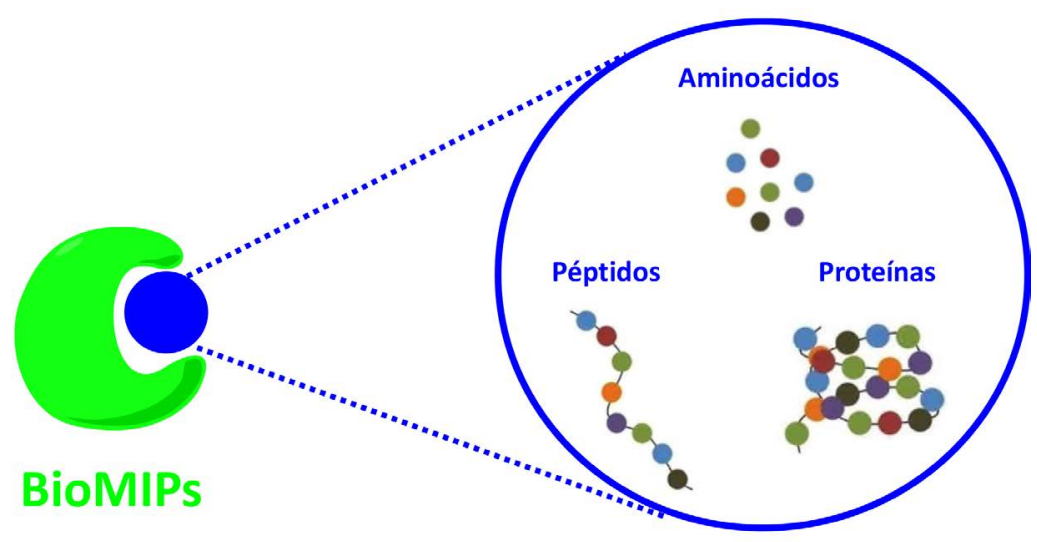

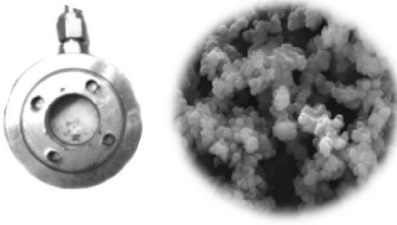

Tecnologias verdes

CleanMIPTech Group, LAQV-FCT/NOVA

Separação/Biopurificação

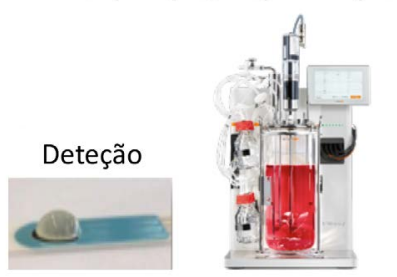

Teresa Casimiro

Referência: PTDC/EQU-EQU/32473/2017.

Financiamento: FCT/MCTES, PIDDAC

(2018-2021).

Equipa: FCT/NOVA - Teresa Casimiro (IR), Raquel

Viveiros (LAQV-REQUIMTE/NOVA), José Luís

Capelo (co-IR), Hugo Santos (UCIBIO-REQUIMTE

/NOVA), Sara Monteiro (CEV).

URL: sites.fct.unl.pt/clean-mip-tech 